\title{
Global Warming Control to Mitigate Climate Change
}

\author{
Antipas T. S. Massawe \\ University of Dar es Salaam, Dar es Salaam, Tanzania \\ Email: massaweantipas@hotmail.com
}

Received January 30, 2012; revised February 27, 2012; accepted March 8, 2012

\begin{abstract}
Paper describes a proposed development of empirical model of global warming fit on the collective determinants in all countries. Aim is to enable establishment and comparison of the collective effects of global determinants on global warming in the prescription of the regulations most fit for the collective deployment in each of the determinant countries to enable mitigation of the greenhouse gases build-up caused global warming.
\end{abstract}

Keywords: Global Population Growth; Greenhouse Gases Build-Up; Global Warming; Climate Change; Empirical Models

\section{Introduction}

\subsection{Global Warming}

Global warming is the rising average temperature of the Earth's atmosphere and oceans which started in the late $19^{\text {th }}$ century and projected to keep going up if measures of mitigation are not put in place [1,2]. As a result of the rise, since the early $20^{\text {th }}$ century, Earth's average surface temperature has increased by about $0.8^{\circ} \mathrm{C}\left(1.4^{\circ} \mathrm{F}\right)$, with about two thirds of the increase occurring since 1980 [2, 3].

\subsection{Greenhouse Gases Build-Up}

Greenhouse gases build-up in the atmosphere is the main suspect cause of most global warming and resulting from the increasing concentrations of greenhouse gases produced by human activities such as the burning of fossil fuels (mostly coal, oil, and gas; plus a few other trace gases) and deforestation [3]. Excessive concentrations of greenhouse gases in the atmosphere causes global warming by absorbing and trapping more heat in the lower atmosphere [3]. Pre-industrial levels of carbon dioxide (prior to the start of the Industrial Revolution) were about 280 parts per million by volume (ppmv), and current levels are greater than $380 \mathrm{ppmv}$ and increasing at a rate of 1.9 $\mathrm{ppm} \cdot \mathrm{yr}^{-1}$ since 2000 . The global concentration of $\mathrm{CO}_{2}$ in our atmosphere today far exceeds the natural range over the last 650,000 years of 180 to $300 \mathrm{ppmv}$. According to the IPCC Special Report on Emission Scenarios (SRES), by the end of the $21^{\text {st }}$ century, we could expect to see carbon dioxide concentrations of anywhere from 490 to 1260 ppm (75\% - 350\% above the pre-industrial concentration) [3].

\subsection{Global Population Growth}

Global population growth which is enhancing (especially in the developing world) is one of the main suspect causes of global warming because it is accompanied by the enhancing greenhouse gases build-up caused by the enhancing human activities in fossil fuels burning (especially in the industrialized world) and deforestation (especially in the developing world) in response to the enhancing number of human beings to feed. Global population growth is enhancing thanks to high fertility rates (especially in the developing world) and the advances in science, medicine and engineering which are more focused on the transformation of the non-renewable global fossil fuel and mineral resources into wealth, mostly to enhance human survivability, comfort and living standards, especially in the developed world.

\subsection{Climate Change}

Climate change is the final result of the global warming caused by the enhancing greenhouse gases build up in the Earth's atmosphere and oceans, also caused by the global population growth which is enhancing. The resultant climate change is dangerous because it hampers the ability of the Earth's environment to continue sustaining the forms of life on the planet, for example, as sea levels rise and the amount and pattern of precipitation change and subtropical deserts expand [3].

\subsection{Empirical Models}

The problem of global warming is therefore a product of the unregulated living activities of human populations and the resultant of multiple cause factors, some of which 
could and should be regulated to enable the desired control of global warming to mitigate climate change and sustain survivability and comfort in all forms of life on the planet.

Since prevention has always been cheaper than cure, priority should be to regulate the responsible human activities in view of overcoming the global warming caused by the enhancing build-up of greenhouse gases in the Earth's atmosphere and oceans.

Therefore, aim in this study is to formulate the theoretical basis for the development of empirical model of global warming fit on the main global determinants of human activities caused greenhouse gases build-up in the atmosphere to enable the identification of global regulations which could be administered to control global warming and the resultant climate change.

\section{Statement of Problem}

Global warming is enhancing due to the enhancing greenhouse gases emission and build-up in the Earth's environment. Result is the climate change which hampers the ability of Earth's environment to enable survivability and comfort in all forms of life on the planet.

The enhancing greenhouse gases emission is mainly a result of the enhancing progress in science, medicine and engineering which is focused on growth in wealth creation and economic prosperity, especially in the developed world where global resources (mainly minerals and energetic resources) are transformed into the manufactured goods on enhancing demand from the enhancing global population growth (especially in the developing world) and living standards (especially in the developed world) [4-6].

The enhancing progress in science, medicine and engineering resulted into the enhancing global population growth and living standards, thanks to the enhancing global growth in wealth creation, economic prosperity and quality of health services, also enhancing immunity to diseases and the other life threatening attacks from nature and the resultant survivability of human beings, especially in the developing world where birth rates remained the same or are enhancing.

The enhancing immunity to diseases and the other life threatening attacks from nature and the resultant survivability of human beings in conditions of constant or enhancing birth rates resulted into the enhancing global population growth and living standards, up at the expense of survivability, growth and comfort in the other forms of life on the planet.

The huge spending of global resources on defense (especially in the wealthiest countries), which could be regarded as the most wasteful and destructive on earth is also enhancing [7,8]. As consumption is enhancing, global reserves of raw materials are also depleting in conditions of enhancing global demand and competitions for them and therefore the need by the wealthiest nations to have strong armies in place on assumption that the enhancing depletion will end up with difficulties of access and therefore wars from which it is the winner who will retain access to the depleting global reserves of raw materials.

Also, the enhancing global population growth and living standards is accompanied with the enhancing demand for the manufacturing of goods which is also accompanied with the enhancing greenhouse gases emission in conditions of diminishing ability of mother Earth to remove them and therefore their enhancing build-up in the Earth's atmosphere and oceans.

The ability of mother earth to remove greenhouse gases build-up in the atmosphere is diminishing mainly because as a result of enhancing global population growth, shrinkage of the global forests responsible for the natural removal of greenhouse gases from the atmosphere is also enhancing as a result of enhancing consumption of forest products for fuel, construction and furniture and forest clearing to pave way for food and cash crop farms on enhancing demand, especially in the developing world.

The enhancing immunity of human beings to diseases and the other life threatening attacks from nature and the resultant survivability on the planet is good but should have also been accompanied with the birth rates aimed at zero or negative rates of global population growth $[9,10]$. This was to sustain natural forests cover on the planet and global demand for manufactured goods and forest products at the level whose rate of greenhouse gases emission doesn't cause build-ups in the Earth's atmosphere and oceans.

\section{Answerable for Problem}

In different ways, all countries in the developed and developing worlds are answerable for the enhancing global population growth and intensification of global activities in wealth creation which are accompanied by the greenhouse gases build-up caused global warming. This is because all human beings on the planet are interdependent and interrelated in their processes of wealth creation and consumption.

Scientists and Engineers are one of the answerable because most of their solutions which are enhancing growth in wealth creation are also responsible for the greenhouse gases build-up caused global warming.

Countries in the developing world are also answerable because they failed to regulate the enhancing population growth and/or mitigate the population growth caused deforestation and the excessive spending of limited resources on militaries in their countries.

Countries in the developed world are also answerable because they are not investing back to the developing 
countries a significant portion of the huge wealth they are generating from the global natural resources extraction they monopolize (especially minerals and energetic resources) in the developing countries to help populations here into those living activities which mean less destruction of the global natural forests.

However, having said that, the large global corporations which appear to be separate from or separated out from Countries and having shareholder value as their sole "modus operandi" need to be addressed in as much as there is little or no democratic control over them and their very size completely outways their value to human enhancement.

Some Cultural and Religious groups are also answerable because of their intolerance to most of the most effective scientific and engineering instruments on disposal for the necessary control of the enhancing global population growth.

Since desire is to sustain the climatic conditions which are necessary for survivability and comfort in all forms of life on the planet, mitigation of the global warming caused by greenhouse gases build-up in the Earth's atmosphere and oceans is a must because it is happening in the suicidal activities of global populations in which the number of human beings to feed is enhancing at the expense of the other forms of life on the planet and its ability to enable survivability and comfort for all forms of life in its environment.

Therefore, aim in the global warming control to mitigate climate change is to achieve greenhouse gases emission and build-up in the Earth's atmosphere and oceans based on the generation and deployment of global solutions to regulate the activities of global population.

\section{Solving the Problem}

The enhancing global warming is determined by many variables, most of which differ from one country to the other and having conflicting effects on the dependent. Some of the determinant variables could be regulated to enable mitigation on the enhancing global warming caused by greenhouse gases build-up in the Earth's atmosphere and oceans.

Consequently, solutions which mitigate the enhancing greenhouses gases build-up caused global warming could be established based on the empirical model of global warming $\left(G_{T},{ }^{\circ} \mathrm{C}\right)$ fit on the main global determinants: population estimate, birth rate, death rate, hydropower consumption, geothermal power consumption, nuclear power consumption, solar power consumption, wind power consumption, bio fuel consumption, coal consumption, oil consumption, gas consumption, defense spending, GDP, greenhouse gases emission estimate, forest coverage estimate, etc., illustrated on (1):

$$
G_{T} \leftrightarrow f\left(\sum_{j=1}^{N} X_{1, j}, \sum_{j=1}^{N} X_{2, j}, \sum_{j=1}^{N} X_{3, j}, \cdots, \sum_{j=1}^{N} X_{M-1, j}, \sum_{j=1}^{N} X_{M, j}\right)
$$

where $X_{i, j}$ is $i$-th determinant in the $j$-th determinant country; $N$ is the total number of determining countries; $M$ is the total number of the determinant variables in individual countries.

Consideration of population estimate, birth rate, death rate, hydropower consumption, geothermal power consumption, nuclear power consumption, solar power consumption, wind power consumption, bio-fuel consumption, coal consumption, oil consumption, gas consumption, defense spending, GDP, greenhouse gases emission estimate and forest coverage estimate as the main suspect determinants is based on the following assumptions:

1) The huge size of global population and its enhancing growth is one of the main contributors to the enhancing global warming.

2) Consumption of hydro, geothermal and nuclear power in place of fossil and bio fuels influenced reduction of greenhouse gases build-up in the Earth's environment and the resultant reduction of global warming.

3) Consumption of oil, coal, gas and bio fuels is one of the main contributors to the enhancing greenhouse gases build-up in the Earth's environment and the resultant global warming.

4) Consumption of geothermal, solar and wind power is one of the main contributors in the reduction of greenhouse gases build-up in the Earth's environment and the global warming.

5) The enhancing deforestation is one of the main contributors to the enhancing greenhouse gases build-up in the Earth's environment and the resultant global warming.

6) Enhanced growth in global wealth creation and military spending are one of the main contributors of global population growth and the resultant greenhouse gases build-up in the Earth's environment caused global warming.

Solutions which mitigate the adverse contribution of individual countries on global warming could also be established from empirical model (1) by replacing on it the global determinants with the determinants in individual countries: population estimate, birth rate, death rate, power consumption, coal consumption, oil consumption, gas consumption, defense spending, GDP, greenhouse gases emission estimate and forest coverage estimate as illustrated on (2).

$$
G_{T j}=f\left(X_{1, j}, X_{2, j}, X_{2, j}, \cdots, X_{M-1, j} X_{M, j}\right)
$$

The empirical model of global warming fit on the determinants of individual countries enables to compare the quantitative contributions of individual countries and 
establish specific regulations for each of the determinant countries and the collective deployment of regulations required to enable global warming control and the desired level of temperature in the atmosphere.

\section{Model Building}

Building up the model could be accomplished based on the recorded global statistics of the variations of global warming $\left(G_{T i(i=1, m d)}\right)$ against the suspect determinants in all determining countries:

$$
\left(\sum_{j=1}^{N} X_{1, j}, \sum_{j=1}^{N} X_{2, j}, \sum_{j=1}^{N} X_{3, j}, \cdots, \sum_{j=1}^{N} X_{M-1, j}, \sum_{j=1}^{N} X_{M, j}\right)_{i(i=1, m d)}
$$

That is,

$$
\begin{aligned}
& G_{T i} \leftrightarrow \\
& \left(\sum_{j=1}^{N} X_{1, j}, \sum_{j=1}^{N} X_{2, j}, \sum_{j=1}^{N} X_{3, j}, \cdots, \sum_{j=1}^{N} X_{M-1, j}, \sum_{j=1}^{N} X_{M, j}\right)_{i(i=1, m d)}
\end{aligned}
$$

where $m d$ is the maximum number of the recorded data variations of global warming against the suspect determinants in all determining countries.

Appropriate software could then be established for the data analysis to establish the correlation-regression of the variations of global warming fit on the global determinants.

\section{Models Utilization}

Once developed, the empirical models will enable application of the theory of decision making in the development of software for the empirical models based computer aided analysis, generation and comparison of the collective contributions of determinants in all and in individual countries on the enhancing global warming and the qualitative and quantitative regulations most fit for the collective deployment to control global warming and mitigate climate change.

\section{REFERENCES}

[1] D. P. Jones and M. L. T. Wigley, "Global Warming Trends," Scientific American, Vol. 263, No. 2, 1990, pp. 84-91. doi:10.1038/scientificamerican0890-84

[2] National Data Center, US Department of Commerce, “Global Warming," Accessed on 22 February 2012. www.ncdc.noaa.gov/6a/climate/globalwarming.html

[3] Intergovernmental Panel on Climate Change (IPCC), "Summary for Policy Makers," 2007, Accessed on 22 February 2012.

http://processtrends/com/P9_GLOBAL_warming,htm

[4] P. Chafurka, "World Energy and Population: Trends to 2010,” Accessed on 21 February 2007. www.paulchefurka.ca/WEAP/WEAP.html

[5] M. O’Brien-Malone, "Ready, Willing and Able: Empowering Countries to Meet the Climate Challenge,” United Nation Environment Programme, New York.

[6] Starmass International, "GDP Growth Rate of Global Top Countries in Terms of GDP," Accessed on 23 February 2012.

www.starmass.om/china-review/global-economy/major-c ountries-GDP.htm

[7] M. R. Greenberg, "Center for Geoeconomic Studies, Trends in US Military Spending,” Council on Foreign Relations, 2011.

[8] World Military Expenditures, “A Compilation of Data and Facts Related to Military Spending, Education and Health," Coordination Office for the Decade to Overcome Violence, World Council of Churches, Geneva, Switzerland, 2005.

[9] UNFPA, "Linking Population, Poverty and Development: Rapid Growth in Less Developed Regions,” Accessed on 22 February 2012. www.unfpa.org/pds/trends.htm

[10] C. Ebden, “UN ‘Concerned’ by World Population Growth Trends,” Accessed on 23 February 2012. www.bbc.co.uk/news/science-environment-12338901 